\title{
Can electrophysiological tests be used as screening tools in detection of cognitive impairment in obstructive sleep apnea hypopnea syndrome?
}

\author{
Mona M. Nada, Eman A. Maher, Mye A. Basheer ${ }^{*}$ (D) and Leqaa A. El-Mekkawy
}

\begin{abstract}
Background: One of the most prevalent sleep disorders is obstructive sleep apnea (OSA). Patients with OSA have increased risk of car and work place accidents which may be attributed to cognitive impairment due to poor sleep quality. Thus, there is an increasing need to implement simple, reliable and rapid screening for cognitive impairment in OSA patients.

Objectives: To assess auditory event-related potentials (ERPS) and quantitative electroencephalography (QEEG) as screening tools for detection of cognitive impairment in OSA patients taking circadian effects into consideration.

Subjects and methods: Twenty OSA patients as well as 20 gender- and age-matched volunteers were subjected to trail making test (TMT), auditory ERPs and QEEG before and after at least $6 \mathrm{~h}$ polysomnographic recording. Correlating electrophysiological tools with TMT and clinical parameters was done as well

Results: Statistically significant changes in P300 latency and reaction time, in addition to occipital alpha power were noted in cases; however, TMT failed to detect such changes. Electrophysiological results were not constantly correlated to clinical parameters.
\end{abstract}

Conclusion: Auditory ERPS and QEEG before and after polysomnography can be of benefit as cognitive screening test for suspected cognitive impairment in OSA patients.

Keywords: Obstructive sleep apnea, Cognitive impairment, Event related potentials, Quantitative EEG, Cognitive screening tests

\section{Introduction}

Impaired cognitive function may arise from interrupted or poor sleep quality resulting from sleep disorders such as obstructive sleep apnea (OSA) [1].

The OSA is responsible for affection deficit, decline of memory and executive dysfunction [2]. This can clarify why OSA patients have up to ten times increased risk of car accidents and at least double risk of workplace accidents $[3,4]$. Identifying at risk patients who are more prone to accidents is clinically challenging due to lack of correlations between symptoms and disease severity [5].

\footnotetext{
* Correspondence: Mye.basheer@kasralainy.edu.eg

Clinical Neurophysiology Unit, Faculty of Medicine, KasrAlainy Hospital, Cairo University, Cairo, Egypt
}

(c) The Author(s). 2020 Open Access This article is distributed under the terms of the Creative Commons Attribution 4.0 International License (http://creativecommons.org/licenses/by/4.0/), which permits unrestricted use, distribution, and reproduction in any medium, provided you give appropriate credit to the original author(s) and the source, provide a link to the Creative Commons license, and indicate if changes were made.
Simple, reliable and rapid screening for cognitive impair-

Late cortical potentials are non-invasive monitoring tools for the cognitive functions [6]. The P300 generation entangles attention and memory-related tasks [7, 8]. Additionally, alpha rhythm is an announced component of brain activity and, thus, presents a preliminary form of data transmission in the brain [9]. Various works researching event-related potentials have assured a directly proportionate relation between alpha frequency from one side and the data processing speed as well as cognitive performance quality $[10,11]$. Clinically, cognition can frequently be assessed using many tools as Mini-Mental State Examination (MMSE) and Trail Making Test (TMT) [12].

\section{Springer Open}


EEG frequencies and P300 wave are variable and changeable according to circadian processes which in turn are responsible for changes in cognitive performance. These alterations are regulated by suprachiasmatic nucleus of the hypothalamus [13], hence more than one recording distributed at day and night might be more sensitive to detect cognitive impairment.

The objective of this study is to assess electrophysiological tests (P300 and quantitative electroencephalography, QEEG) as screening tools for detection of cognitive impairment in OSA patients and correlating them with symptoms and disease severity. Circadian effect on these tests is to be studied as well to optimize timing of performance.

\section{Subjects and methods}

This is an observational case control study, carried out on 20 OSA patients as well as 20 healthy sex- and agematching volunteers. Subjects were recruited from the University Hospitals, in the period from January 2015 to January 2017. The study was conducted at the Clinical Neurophysiology lab of the University Hospitals. The experimental method was approved by the Faculty Research Ethics Committee on May 30th, 2015; a written consent was signed by the subjects, and a clinical trial registration number was issued.

This study included subjects who were more than 18 years old, suffering from symptoms suggestive of excessive daytime sleepiness (EDS) according to the international classification of sleep disorder defintion, having an Epworth Sleepiness Scale (ESS) score of more than 10 [14], normal neurological examination and with Apnea Hypopnea Index (AHI) of more than 5.

Subjects having EDS secondary to any other sleep disorder; chronic deblitating disease; EEG slowing; on medications that could affect attention or vigiliance as benzodiazepines, anti-psychotics or stimulants; and MMSE of less than 27 were excluded.

Subjects were submitted to clinical assessment (history taking including complaint analysis, history of drug intake, body mass index calculation as well as general and neurological examination), MMSE [15]. and ESS [16].

As well, subjects performed sleep study (polysomnography, PSG); the used machine was a digital package (Somnologica, USA) with serial number (F131036-SL) and version 3.2 (Build 1451) on a personal computer, using Microsoft windows $\mathrm{XP}^{\circ}$ platform. Night PSG was done with $6-8 \mathrm{~h}$ average duration of recording. All traces were manually scored in 30-s epochs according to the recommendations of the American Academy of Sleep Medicine (AASM) Manual for the scoring of sleep and associated events [17].

TMTs A and B, P300 and QEEG were performed before and after sleep. The TMT evaluates cognitive state of the patients at a certain moment. They were done just before sleep and $45 \mathrm{~min}$ after wakefulness to avoid sleep inertia [18]. For Scoring Trails A and B tests, a time over $3 \mathrm{~min}$ or $>1$ error respectively is a failure.

As for P300 potential, it was recorded using auditory oddball paradigm in which the subject was instructed to press a button whenever he hears the rare target tones which are randomly mixed with the common standard tones. The frequency of the common tone was $2 \mathrm{KHz}$, while that of the rare tone was $1 \mathrm{KHz}$ with a total number of 150 tones divided into $30(20 \%)$ rare and $120(80 \%)$ common tones, intensity of all tones were adjusted at $85 \mathrm{~dB}$. The used machine is Nihon Kohden, Japan; Neuropak MEB9200G/K EP/EMG measuring system (Neuropak M1)4 channels-versions 08.11 . The surface scalp electrodes where applied according to the 10-20 international system with active electrode at $\mathrm{Cz}$, reference at either mastoid (M) processes and a ground electrode on the forehead. The electrode impedance was kept below $5 \mathrm{~K} \Omega$. The gain was initially set at $50 \mu \mathrm{V}$ per (vertical) division, the monitor time was $0.2 \mathrm{~s}$ and the band pass was $0.1 \mathrm{~Hz}$ (low cut) and $50 \mathrm{~Hz}$ (high cut). For each subject, the P300 latency, amplitude and reaction time (RT) were obtained before and after sleep study.

Finally, EEG recording was carried out while the patient was lying in a dorsal recumbent position, in a semi-illuminated quiet room, with his eyes gently closed. In a separate control room, the video EEG was continuously monitored by a technologist, utilizing a videoelectroencephalograph system with an EB-Neuro Galileo NT, PMS, USA machine (its serial number is DAUNL7HQ4NUSFG with model Mizar.B8351037899.Version 3.61). A cap was used for recording. The high frequency filter was $70 \mathrm{~Hz}$, and time constant was $0.3 \mathrm{~s}$. The impedance was kept below $5 \mathrm{~K} \Omega$.EEG was done for $30 \mathrm{~min}$ duration before and after sleep recording. Artifact-free epoch of 10-s duration in a common average reference montage was selected for QEEG analysis, during wakefulness resting state with closed eyes. These epochs were selected from EEG record which was done twice; before and after sleep.

The absolute power of 2 electrodes (O1 and O2) was studied in the alpha band [8-13] c/s. In each EEG recording, alpha attenuation test (AAT) was done after 10 min of recording basal resting EEG. In this test, the participants were instructed to open their eyes and stare at a small postcard on the wall for $2 \mathrm{~min}$ then close their eyes again. This test depends on the fact that alpha waves are evoked mainly in the occipital region with relaxation closing the eyes and attenuates when the subject opens his eyes and concentrates in any task so the power of alpha band during this test is decreased. The test is performed to insure a high arousal level [19]. 


\section{Statistical analysis}

Data were coded and entered using the statistical package Statistical Package for the Social Sciences (SPSS; IBM SPSS Statistics for Windows, Version 24.0, 2016; Armonk, NY: IBM Corp.). Data were summarized using mean, standard deviation, median, minimum and maximum in quantitative data and frequency (count) and relative frequency (percentage) for categorical data. Quantitative variables comparisons were done using the non-parametric Mann-Whitney test. The non-parametric Wilcoxon signed rank test was used for serial measurements within each patient [20]. For comparing categorical data, chi square $\left(x^{2}\right)$ test was performed. Exact test was used instead when the expected frequency is less than 5 [21]. Spearman correlation coefficient was used for quantitative variable correlations [22].

\section{Results}

The study group included 20 cases (4 females and 16 males) with mean age of $45.45 \pm 7.6$ years and the BMI mean was $31.97 \pm 4.26 \mathrm{~kg} / \mathrm{m}^{2}$. While the control group included 20 subjects (5 females and 15 males), with a mean age of $41.95 \pm 7.29$ years and their body mass index (BMI) mean of $29.58 \pm 5.64 \mathrm{~kg} / \mathrm{m}^{2}$. There were no statistically significant difference regarding age, BMI and gender, with $P$ value $=0.151,0.076$ and 1.0, respectively.

The PSG of all cases showed OSA syndrome with Apnea-hypopnea index (AHI) mean value $20.26 \pm 9.26 / \mathrm{h}$ and sleep efficiency mean value $88.01 \pm 11.80 \%$, while the control group had AHI mean value of $1.52 \pm 1.66 / \mathrm{h}$ and mean sleep efficiency of $83.01 \pm 9.16 \%, \pm 0.66$. Sleep efficiency (\%) showed no significant difference between both groups.

All cases had normal MMSE with mean value of $29.45 \pm 0.89$; as for the controls, MMSE was 29.70. No statistically significant difference between both groups $(P$ value $=0.29$ ).

The ESS was markedly higher in cases than the control groups with high statistically significant difference $(P<0.001), \quad 14.5 \pm 4.98$ in cases compared to $2.20 \pm 2.07$ in controls.
Comparing "the before sleep P300 and TMT" as well as "the after sleep P300 and TMT" of both groups are shown in Table 1.

The P300 latency and mean RT-both measured in milliseconds-after sleep were significantly earlier than its value before sleep with statistically significant difference $(P$ value $<0.001)$, but comparison of P300 amplitude before sleep $(9.16 \pm 5.33 \mu \mathrm{V})$ with that after sleep $(10.07 \pm 5.81 \mu \mathrm{V})$ showed no significant difference $(P=$ 0.441 ). Additionally, there was significant reduction of duration of TMTA and B-measured in seconds-results after sleep in comparison to that before sleep with $P=0.044$ and $P<0.001$, respectively.

The mean of P300 latency-measured in milliseconds-was more delayed after sleep than that before it, showing highly significant difference $(P<0.001)$. Additionally, the RT-measured in milliseconds-value was more prolonged after sleep than before it, giving a highly significant difference $(P<0.001)$. Also, no significant difference $(P=0.07)$ was detected in comparing P300 amplitude before $(12.0 \pm 7.87 \mu \mathrm{V})$ with after sleep $(16.20 \pm$ $9.67 \mu \mathrm{V})$. Finally, comparison of TMTA and B resultsmeasured in seconds-showed reduction of its duration after sleep, with high statistically significant difference $(P<0.001)$.

Table 2 shows the comparison of EEG epochs during resting state and also during AAT between the case and control groups before and after sleep in the average of occipital alpha band.

No significant correlations were found between TMT results and P300 latency difference, RT and occipital alpha difference in the case group. Also, no significant correlation was found between occipital alpha difference and P300 latency difference. $(P=0.408 ; r=0.196)$.

Correlations of electrophysiological tools with clinical parameters (ESS and AHI) showed that occipital alpha difference has a significant positive correlation in cases with ESS $(P=0.022, r=0.509)$ and no significant correlation with AHI $(P=0.167)(r=0.321)$.

Regarding P300 latency difference in cases-measured in milliseconds-a significant positive correlation was

Table 1 Comparison between P300 and TMT in cases and controls

\begin{tabular}{|c|c|c|c|c|c|c|c|c|c|c|}
\hline & \multicolumn{5}{|c|}{ Before sleep } & \multicolumn{5}{|c|}{ After sleep } \\
\hline & \multicolumn{2}{|c|}{ Cases $(n=20)$} & \multicolumn{2}{|c|}{ Control $(n=20)$} & \multirow{2}{*}{$\begin{array}{l}P \\
\text { value }\end{array}$} & \multicolumn{2}{|c|}{ Cases $(n=20)$} & \multicolumn{2}{|c|}{ Control $(n=20)$} & \multirow{2}{*}{$\begin{array}{l}P \\
\text { value }\end{array}$} \\
\hline & Mean & SD & Mean & SD & & Mean & SD & Mean & SD & \\
\hline P300 L (ms) & 346.15 & 27.39 & 371.00 & 28.84 & $0.018^{*}$ & 369.85 & 22.92 & 351.60 & 26.27 & $0.02^{*}$ \\
\hline P300 A $(\mu \mathrm{V})$ & 12.00 & 7.87 & 9.16 & 5.33 & 0.289 & 16.20 & 9.67 & 10.07 & 5.81 & $0.013^{*}$ \\
\hline Mean RT (ms) & 507.30 & 131.85 & 491.65 & 78.31 & 0.221 & 596.95 & 135.84 & 464.30 & 93.65 & $0.003^{*}$ \\
\hline TMT A (s) & 89.80 & 40.39 & 80.50 & 29.71 & 0.718 & 70.40 & 38.20 & 73.05 & 25.39 & 0.369 \\
\hline TMT B (s) & 122.60 & 32.05 & 118.75 & 29.94 & 0.698 & 103.95 & 29.48 & 101.85 & 29.34 & 0.64 \\
\hline
\end{tabular}

$L$ latency, $m s$ millisecond, $A$ amplitude, $\mu V$ microvolt, $R T$ reaction time, $T M T$ trail making test, $s$ second

*Statistically significant 
Table 2 Comparison of occipital alpha power baseline and AAT within each of cases and controls

\begin{tabular}{llll}
\hline & $\begin{array}{l}\text { Median } \\
\text { before sleep }\end{array}$ & $\begin{array}{l}\text { Median } \\
\text { after sleep }\end{array}$ & $P$ value \\
\hline Average alpha $\mathrm{O}\left(\right.$ baseline $\left.\mu \mathrm{V}^{2}\right)$ in control & 6.76 & 18.37 & 0.97 \\
Average alpha $\mathrm{O}\left(\mathrm{AAT} \mu \mathrm{V}^{2}\right)$ in control & 1.80 & 2.45 & 0.709 \\
Average alpha $\mathrm{O}\left(\right.$ baseline $\left.\mu \mathrm{V}^{2}\right)$ in cases & 18.07 & 12.68 & $0.03^{*}$ \\
Average alpha $\mathrm{O}\left(\mathrm{AAT} \mu \mathrm{V}^{2}\right)$ in cases & 1.95 & 2.36 & 0.1 \\
\hline
\end{tabular}

$O$ occipital, $\mu V^{2}$ squared microvolt; power, AAT Alpha Attenuation Test

*Statistically significant

found between it and AHI $(P=0.016, r=0.532)$. No significant correlation was found between RT difference and AHI $(P=0.079, r=0.402)$. Also, no significant correlation was found between P300 latency difference and ESS ( $P$ value $=0.340, r=0.225)$ or RT difference and the ESS $(P=0.454, r=0.177)$.

Finally, correlation between each sleep stage percentage (S1, S2, S3 and REM) of each patient, with P300 latency difference between (before and after) sleep in milliseconds, P300 reaction time difference between (before and after) sleep in milliseconds and average baseline occipital alpha power $\left(\mu \mathrm{V}^{2}\right)$ in cases, is shown in Table 3.

\section{Discussion}

Screening tools for patients of OSA are required to detect those with cognitive affection as there is a discrepancy between severity of disease and cognition impairment. This screening may be applied especially to population at risk like drivers, shift workers, people with transportation jobs and health care professionals [14, 23].
There are different methods used to detect this cognitive impairment like driving simulators which are the gold standard but is time consuming, expensive, and not easily available in all health facilities [24]; others include psychomotor vigilance test (PVT), one of the leading paradigms used to test vigilant attention, which is easily applicable in clinical populations, but with the presence of a motor response, represents difficulties in use in uncooperative patients [25].

Event-related potentials (ERPs) have been used as a neurophysiological marker of information processing, discrimination, and working memory [26].

Furthermore, QEEG techniques have been used in differentiation between cognitive impairment and normal aging especially when the abnormality is rather borderline or subtle [27]. QEEG also has been validated as a reliable indicator of mild cognitive impairment (MCI) [28].

P300 shows significant diurnal variations in P300 latency and amplitude at $\mathrm{Pz}$ was observed; it was found that P300 latency was significantly longer at 08:00 than at 11:00, 17:00, and 20:00. Also, it was found that P300

Table 3 Correlation between sleep stage percentages with P300 differences and average baseline occipital alpha power

\begin{tabular}{|c|c|c|c|c|}
\hline & S1 (\%) & $\mathrm{S} 2(\%)$ & S3 (\%) & REM \\
\hline \multicolumn{5}{|l|}{ P300 latency difference } \\
\hline Correlation coefficient & 0.326 & -0.352 & -0.046 & -0.178 \\
\hline$P$ value & 0.173 & 0.140 & 0.852 & 0.465 \\
\hline \multicolumn{5}{|c|}{ P300 reaction time difference } \\
\hline Correlation coefficient & -0.133 & -0.077 & 0.218 & -0.060 \\
\hline$P$ value & 0.586 & 0.753 & 0.370 & 0.807 \\
\hline \multicolumn{5}{|c|}{ Average $O$ alpha (baseline power before sleep) } \\
\hline Correlation coefficient & 0.014 & 0.240 & -0.125 & -0.113 \\
\hline$P$ value & 0.955 & 0.323 & 0.611 & 0.644 \\
\hline \multicolumn{5}{|c|}{ Average $O$ alpha (baseline power after sleep) } \\
\hline Correlation coefficient & -0.035 & 0.258 & -0.021 & -0.065 \\
\hline$P$ value & 0.887 & 0.286 & 0.932 & 0.790 \\
\hline \multicolumn{5}{|l|}{ Average $\mathrm{O}$ alpha difference } \\
\hline Correlation coefficient & 0.030 & -0.194 & 0.290 & -0.039 \\
\hline$P$ value & 0.904 & 0.426 & 0.228 & 0.874 \\
\hline
\end{tabular}


latency was prolonged after sleep deprivation as occurred in OSA patients [29]. Regarding QEEG, it is affected by this circadian process; during wakefulness, it shows marked circadian variation in nearly all frequencies. It was found that the decrease in alpha activity during wakefulness is corresponding to wake-dependent reduction in alertness and cognitive functions [30].

The aim of the current study was to assess electrophysiological tests (P300 and QEEG) as screening tools for detection of cognitive affection in OSA patients and correlating them with symptoms and disease severity. Circadian effect on these tests is to be studied as well to optimize timing of performance.

In the current study, the case group demography agrees with literature. The higher male percentage is in agreement with Strohl and Redline's findings [31]. The relatively old age agrees with [32], who hypothesized that risk of having OSA increases with age which may be due to increased length of the soft palate, fat deposition in the para-pharyngeal region and changes in body structures that surround the pharyngeal tissue [33]. Finally, regarding the high $\mathrm{BMI}$, this comes in agreement with the worldwide epidemiologic studies about body weight $\left(\mathrm{BMI}>25 \mathrm{~kg} / \mathrm{m}^{2}\right.$ ), which was considered as the strongest risk factor for OSA [34]. Punjabi in 2008 stated that every $10 \%$ increase in the body weight leaded to an increase of the AHI by $32 \%$ and a six-fold increase in the risk of developing AHI to severe OSA.

In the current study, P300 latency and RT in the cases were prolonged than controls (regarding the comparison of after-sleep results). Clinically, it was found that as the sleep became more disrupted and fragmented, the performance on attention and vigilance tests in addition to memory and learning became more impaired [35].

In contrast to previous studies, the P300 latency was significantly earlier in the cases compared to the controls (regarding before-sleep results comparison). Authors suggest that normal circadian changes of cognition in controls showed the least level of cognition before sleep and highest level would be after their sufficient night sleep, so that disruption of this normal circadian change in the cases could demonstrate unexpected P300 latency before sleep in cases.

Comparison of the P300 amplitude between cases and control before sleep showed no significant difference, but when comparing the case and control groups P300 results after sleep, it was found that the amplitude of P300 is relatively higher in the cases than its corresponding value in the control group. This could be explained by the relatively more synchronized electrical brain status in cases than in controls due to their morning drowsiness compared to more vigilance of the control group. This is supported by previous suggestion that EEG content was still close to sleep, so that the more synchronized the EEG after awakening, the more the reduced level of arousal and the more deficient the performance speed and accuracy in sleep-deprived patients and only performance speed affection in normal people [36].

Comparison of P300 amplitudes before and after sleep within each of the case and control groups showed no significant difference. This agrees with Cote and colleagues' study [37] that showed that there were no changes in P300 amplitude recording after two nights of sleep fragmentation. On the other hand, current results contradicts El Gohary and colleagues' results, that showed reduction of P300 amplitude recorded after sleep than its result before sleep in the cases with OSA, while the control group showed increase in P300 amplitude after sleep than before it [38]. These heterogeneous findings may reflect the different sensitivity of the P300 to variable manipulations such as sleep fragmentation [39]. Also, it was found that a single measurement of P300 may not be enough and that several recordings may unmask subtle changes [38].

In our study, comparison of after sleep P300 values to before it in the cases, revealed that non-restorative fragmented sleep led to prolongation of P300 latency and RT values. Our results agreed with other studies that reported prolongation of P300 latency in OSA patients, with persistence of these abnormal changes months, even, after treatment with continuous positive airway pressure (CPAP) [40].

Regarding results of QEEG analysis in the cases, they showed significant reduction of the average absolute power $\left(\mu \mathrm{V}^{2}\right)$ of occipital alpha after sleep than before it $(P<0.025)$, while the control group showed no significant change in their alpha power after sleep in comparison to before results.

This agrees with results of D'Rozario and colleagues' study, which was done for OSA patients. In such study, resting awake EEG with closed eyes was recorded every $2 \mathrm{~h}$, after $40 \mathrm{~h}$ of extended wakefulness (using 6 referential derivations $\mathrm{C} 3, \mathrm{C} 4, \mathrm{Fz}, \mathrm{Cz}, \mathrm{Pz}, \mathrm{Oz}$ ). QEEG analysis of those patients with OSA showed significantly lower mean power of alpha frequency band than that of the control group [41]. Such EEG changes represent reduction of vigilance of OSA patients [42].

Furthermore, results were similar to those of Smith and colleagues', who studied the effect of overnight extended wakefulness on EEG in healthy subjects and 540 min resting EEG recording sessions with eyes closed (from 11:00 pm to 5:00 am) were done. Decreased occipital alpha power over the occipital region was noticed indicating the classic signs of drowsiness (that increased approximately linearly over the course of studied night), which demonstrated and supported absolute alpha power reduction in current study cases as well as demonstrated the insignificant changes in alpha power in the control group [43]. 
In agreement with the current study, QEEG results, those of Kwak's study, where there was reduction of alpha power in patients with mild cognitive impairment (MCI) in comparison with elderly subjects without $\operatorname{cog}$ nitive complaints [44].

Grenèche and colleagues' study results were contrary to previous results as regard the absolute alpha power in OSA patients after $24 \mathrm{~h}$ of sleep deprivation [45]. It was obviously higher in OSA patients in comparison to that in controls. This increase in alpha power may be demonstrated by the compensatory process hypothesis which was contrary to our result hypothesis and stated that sleep-deprived subjects pay much effort to stay awake and prevent their sleepiness, leading to paradoxical rebound of alpha EEG power [46].

The mechanism of the reduction of alpha power in OSA patients after sleep could be attributed to hypoxia occurring during sleep in such patients (especially those with severe type) that causes slowing of EEG power [42]. Also, P300 affection in our patients of OSA could be attributed to recurrent nocturnal hypoxemia. Hypoxemia leads to neuronal damage in multiple brain regions as frontal lobe. Significant association was found between hypoxemia and some cognitive deficits in the form of impaired attention, slow speed of information processing and executive dysfunctions [47].

In the current study, TMT results of the case and control groups (before-with-before and after-with-after sleep) showed no statistically significant differences. Also, before-to-after sleep comparison failed to detect any abnormality; on the contrary, they improved after sleep. This agrees with results of Gelir and colleagues, who investigated the effect of OSA on cognition. Their TMT results showed no statistically significant difference between patient and control groups in any of TMT-A trial or the first or second trials of TMT-B [48].

A significant positive correlation was found in the cases of this study between the difference of average occipital $(\mathrm{O})$ alpha power and ESS score, which agrees with Xiromeritis and colleagues, who studied the correlation between ESS score and alpha relative power in OSA patients and recorded the EEG during wakefulness in the morning $(8 \mathrm{am})$ after polysomnographic recording in the previous night [49].

Another significant positive correlation was found in our study between P300 latency difference (between before and after sleep) and AHI in the cases. This is in agreement with the result of Zou and colleagues' study which found a significant positive correlation between P300 latency and AHI in OSA patients [50]. Contrary to this result was that found by Inoue and colleagues, who studies the correlation between P300 latency (which was done just prior to MSLT recording at 14:00) and apneahypopnea index and arousal index in untreated severe
OSA patients and found no correlation [51]. This contrary result may be due to the use of patient with different disease severity or the use of value of only single recording of P300, not the difference between before and after sleep values in our study.

However, some limitations of the current study should be noted. First limitation is that the study included patients with mild and moderate sleep apnea. The lack of severe sleep apnea cases did not allow comparison of severity of cognitive impairment among all groups of apnea patients. Second one is that the results of sleep efficiency analysis were more or less in the normal range, which comes along with the beforementioned limitation of lack of severe cases. Thus, further studies in this domain, on a larger number of patients, are strongly recommended.

\section{Conclusion}

Evening as well as morning recording of P300 latency, RT and occipital alpha is more sensitive than a single recording in detecting cognitive impairment in OSA patients. However, P300 amplitude and TMT tests are not sensitive tools for screening of cognitive impairment in OSA patients.

Adding auditory ERPs and QEEG before and after PSG test, requested for suspected OSA, can be used as rapid screening for cognitive impairment as AHI and ESS score do not necessarily reflect cognitive state.

\section{Abbreviations}

AAT: Alpha attenuation test; AHI: Apnea-hypopnea index; EDS: Excessive daytime sleepiness; ESS: Epworth Sleepiness Scale; MMSE: Mini-Mental State Examination; OSA: Obstructive sleep apnea; PSG: Polysomnography; QEEG: Quantitative electroencephalography; RT: Reaction time; TMT: Trail making tests

\section{Acknowledgements}

Not applicable.

\section{Authors' contributions}

LAE performed electrophysiological and clinical studies, collected the data and assisted in writing the manuscript; MAB made the study design, supervised electrophysiological studies, reviewed and analyzed the data and drafted the manuscript; EAM made the study design, supervised the electrophysiological studies, reviewed the data and drafted the manuscript; MMN supervised electrophysiological studies, reviewed the data and revised the manuscript draft. All authors read and approved the final manuscript.

\section{Funding}

No funding

\section{Availability of data and materials}

Findings on which the conclusions of the manuscript rely are summarized in the manuscript. For further inquiries, please contact the corresponding author.

\section{Ethics approval and consent to participate}

The study was approved by the ethical committee of the Department of Neurology and Clinical Neurophysiology, Faculty of Medicine, Cairo

University on May 30th, 2015. All subjects provided informed written consent to participate in the study. The clinical trial registration number is NCT03446066. 


\section{Consent for publication}

Not applicable.

\section{Competing interests}

The authors declare that they have no competing interests.

\section{Received: 9 April 2019 Accepted: 10 February 2020} Published online: 19 February 2020

\section{References}

1. Chen I, Vorona R, Chiu R, Ware JC. A survey of subjective sleepiness and consequences in attending physicians. Behav Sleep Med. 2008;6(1):1-15.

2. Bawden FC, Oliveira CA, Caramelli P. Impact of obstructive sleep apnea on cognitive performance. ArqNeuropsiquiatr. 2011;69(4):585-9.

3. Lindberg E, Carter N, Gislason T, Janson C. Role of snoring and daytime sleepiness in occupational accidents. Am J RespirCrit Care Med. 2001; 164(11):2031-5.

4. George CF. Sleep apnea, alertness, and motor vehicle crashes. Am J RespirCrit Care Med. 2007;176(10):954-6.

5. Quan SF, Chan CS, Dement WC, Gevins A, Goodwin JL, Gottlieb DJ, et al The association between obstructive sleep apnea and neurocognitive performance - the apnea positive pressure long-term efficacy study (APPLES). Sleep. 2011;34(3):303-314B.

6. Duncan CC, Barry RJ, Connolly JF, Fischer C, Michie PT, Näätänen R, et al. Event-related potentials in clinical research: guidelines for eliciting recording and quantifying mismatch negativity, P300, and N400. Clin Neurophysiol. 2009;120:1883-908.

7. Bledowski C, Prvulovic D, Goebel R, Zanella F, Linden D. Attentional systems in target and distracter processing: a combined ERP and fMRI study. Neuroimage. 2004;22(2):530-40.

8. Polich J. Updating P300: an integrative theory of P3a and P3b. Clin Neurophysiol. 2007;118(10):2128-48.

9. Klimesch W. EEG alpha and theta oscillations reflect cognitive and memory performance: a review and analysis. Brain Res Rev. 1999;29(2-3):169-95.

10. Krause CM, Sillanmäki L, Koivisto M, Häggqvist A, Saarela C, Revonsuo A, et al. Effects of electromagnetic field emitted by cellular phones on the EEG during a memory task. Neuroreport. 2000;11(4):761-4.

11. Laufs H, Krakow K, Sterzer P, Eger E, Beyerle A, Salek-Haddadi A, et al. Electroencephalographic signatures of attentional and cognitive default modes in spontaneous brain activity fluctuations at rest. Proc Natl Acad Sci USA. 2003;100(19):11053-8.

12. Ismail Z, Rajji TK, Shulman Kl. Brief cognitive screening instruments: an update. Int J Geriatr Psychiatry. 2010;25(2):111-20.

13. Cajochen C, Wyatt JK, Czeisler CA, Dijk DJ. Separation of circadian and wake duration-dependent modulation of EEG activation during wakefulness. Neuroscience. 2002;114(4):1047-60

14. Boulos MI, Murray BJ. Current evaluation and management of excessive daytime sleepiness. Can J NeurolSci. 2010;37(2):167-76.

15. Folstein MF, Folstein SE, McHugh PR. "Mini-mental state": a practical method for grading the cognitive state of patients for the clinician. J Psychiatr Res. 1975;12:189-98

16. Johns MW. A new method for measuring daytime sleepiness: the Epworth sleepiness scale. Sleep. 1991;14(6):540-5.

17. Philip P, Chaufton C, Taillard J, Sagaspe P, Leger D, Raimondi M, et al. Maintenance of wakefulness test scores and driving performance in sleep disorder patients and controls. Int J Psychophysiol. 2013;89(2):195-202.

18. Tombaugh TN. Trail making test A and B: normative data stratified by age and education. Arch ClinNeuropsych. 2004;19:203-14.

19. Nozawa A, Tacano M. Correlation analysis on alpha attenuation and nasal skin temperature. J Stat Mech-Theory. 2009;2009(01):P01007.

20. Chan YH. Biostatistics 102: quantitative data - parametric and nonparametric tests. Singap Med J. 2003a:44(8):391-6.

21. Chan YH. Biostatistics 103: qualitative data -tests of independence. Singap Med J. 2003b:44(10):498-503.

22. Chan YH. Biostatistics 104: correlational analysis. Singap Med J. 2003c;44(12): 614-9.

23. Karimi M, Eder DN, Eskandari D, Zou D, Hedner JA, Grote L. Impaired vigilance and increased accident rate in public transport operators is associated with sleep disorders. Accid Anal Prev. 2013;51:208-14.
24. Turkington PM, Sircar M, Allgar V, Elliott M. W. Relationship between obstructive sleep apnoea, driving simulator performance, and risk of road traffic accidents. Thorax. 2001;56(10):800-5.

25. Basner M, Dinges DF. Maximizing sensitivity of the psychomotor vigilance test (PVT) to sleep loss. Sleep. 2011;34(5):581.

26. Sforza E, Haba-Rubio J. Event-related potentials in patients with insomnia and sleep-related breathing disorders: evening-to-morning changes. Sleep. 2006;29(6):805-13.

27. Besthorn C, Zerfass R, Geiger-Kabisch C, Sattel H, Daniel S, Schreiter-Gasser $U$, Förstl H. Discrimination of Alzheimer's disease and normal aging by EEG data. ElectroencephalogrClinNeurophysiol. 1997;103(2):241-8.

28. Jackson CE, Snyder PJ. Electroencephalography and event-related potentials as biomarkers of mild cognitive impairment and mild Alzheimer's disease. Alzheimers Dement. 2008;4(1 Suppl 1):S137-43.

29. Higuchi S, Liu Y, Yuasa T, Maeda A, Motohashi Y. Diurnal variation in the P300 component of human cognitive event-related potential. Chronobiollnt. 2000;17(5):669-78

30. Wyatt JK, Cecco AR, Czeisler CA, Dijk DJ. Circadian temperature and melatonin rhythms, sleep, and neurobehavioral function in humans living on a 20-h day. Am J Physiol Regul Integr Comp Physiol. 1999;277(4Pt 2):R1152-63.

31. Strohl K, Redline S. Recognition of obstructive sleep apnea. Am J RespirCrit Care Med. 1996;154(2):274-89.

32. Punjabi NM. The epidemiology of adult obstructive sleep apnea. Proc Am ThoracSoc. 2008:5(2):136-43.

33. Eikermann M, Jordan AS, Chamberlin NL, Gautam S, Wellman A, Lo YL, et al. The influence of aging on pharyngeal collapsibility during sleep. Chest. 2007;131(1):1702-9.

34. Tufik S, Santos-Silva R, Taddei JA, Bittencourt LR. Obstructive sleep apnea syndrome in the Sao Paulo epidemiologic sleep study. Sleep Med. 2010; 11(5):441-6.

35. Bucks RS, Olaithe M, Eastwood P. Neurocognitive function in obstructive sleep apnea: a meta-review. Respirology. 2013;18(1):61-70.

36. Tassi P, Bonnefond A, Engasser O, Hoeft A, Eschenlauer R, Muzet A. EEG spectral power and cognitive performance during sleep inertia: the effect of normal sleep duration and partial sleep deprivation. PhysiolBehav. 2006 87(1):177-84.

37. Cote KA, Milner CE, Osip SL, Ray LB, Baxter KD. Waking quantitative electroencephalogram and auditory event-related potentials following experimentally induced sleep fragmentation. Sleep. 2003;26(6):687-94.

38. El Gohary A, El Habashy H, Mostafa S, Maher E, Helmy S. P1100: Eventrelated potentials in sleep-related breathing disorders and insomnia. Clin Neurophysiol. 2014;125:S330.

39. Colrain IM, Campbell KB. The use of evoked potentials in sleep research. Sleep Med Rev. 2007;11(4):277-93.

40. Durmer JS, Dinges DF. Neurocognitive consequences of sleep deprivation. In SeminNeurol. 2005;25(1):117-29.

41. D'Rozario AL, Kim JW, Wong KK, Bartlett DJ, Marshall NS, Dijk DJ, et al. A new EEG biomarker of neurobehavioural impairment and sleepiness in sleep apnea patients and controls during extended wakefulness. Clin Neurophysiol. 2013;124(8):1605-14.

42. Saletu B, Grünberger J, Anderer P, Linzmayer L, König P. On the cerebroprotective effects of caroverine, a calcium-channel blocker and antiglutamatergic drug: double-blind, placebo controlled, EEG mapping and psychometric studies under hypoxia. Br J ClinPharmacol. 1996;41(2):89-99.

43. Smith ME, McEvoy LK, Gevins A. The impact of moderate sleep loss on neurophysiologic signals during working-memory task performance. Sleep. 2002:25(7):56-66.

44. Kwak YT. Quantitative EEG findings in different stages of Alzheimer's disease. J ClinNeurophysiol. 2006;23(5):457-62

45. Grenèche J, Krieger J, Erhardt C, Bonnefond A, Eschenlauer A, Muzet A, et al EEG spectral power and sleepiness during $24 \mathrm{~h}$ of sustained wakefulness in patients with obstructive sleep apnea syndrome. Clin Neurophysiol. 2008; 119(2):418-28.

46. Lorenzo I, Ramos J, Arce C, Guevara MA Corsi-Cabrera M. Effect of total sleep deprivation on reaction time and waking EEG activity in man. Sleep. 1995:18(5):346-54.

47. Gagnon K, Baril AA, Gagnon JF, Fortin M, Decary A, Lafond C, et al. Cognitive impairment in obstructive sleep apnea. PatholBiol. 2014:62(5):233-40.

48. Gelir E, Başaran C, Bayrak S, Yağcıoğlu S, Budak MT, Fırat H, et al. Electrophysiological assessment of the effects of obstructive sleep apnea on cognition. PLoS One. 2014;9(2):e90647. 
49. Xiromeritis AG, Hatziefthimiou AA, Hadjigeorgiou GM, Gourgoulianis KI, Anagnostopoulou DN, Angelopoulos NV. Quantitative spectral analysis of vigilance EEG in patients with obstructive sleep apnea syndrome. Sleep Breath. 2011;15(1):121-8.

50. Zou K, Sun Y, Tang X, Lei F, Du L, Chen Z, et al. Early signs of cognitive impairment in patients with obstructive sleep apnea hypopnea syndrome: an event-related potential study. Sheng Wu Yi Xue Gong Cheng XueZaZhi. 2014;31(4):870-4.

51. Inoue Y, Nanba K, Kojima K, Mitani H, Arai A. H. P300 abnormalities in patients with severe sleep apnea syndrome. Psychiatry ClinNeurosci. 2001; 55(3):247-8

\section{Publisher's Note}

Springer Nature remains neutral with regard to jurisdictional claims in published maps and institutional affiliations.

\section{Submit your manuscript to a SpringerOpen ${ }^{\mathcal{O}}$ journal and benefit from:}

- Convenient online submission

- Rigorous peer review

- Open access: articles freely available online

- High visibility within the field

- Retaining the copyright to your article

Submit your next manuscript at $\boldsymbol{\nabla}$ springeropen.com 